Georgia State University

ScholarWorks @ Georgia State University

\title{
Relationship Between Home Literacy Environment and Reading Achievement in Children with Reading Disabilities
}

\author{
Robin Morris \\ Georgia State University, robinmorris@gsu.edu \\ Rose Sevcik \\ Georgia State University, rsevcik@gsu.edu \\ Fontina Rashid \\ Georgia State University, frashid@atlantaspeechschool.org
}

Follow this and additional works at: https://scholarworks.gsu.edu/psych_facpub

Part of the Psychology Commons

\section{Recommended Citation}

Rashid, F.L., Morris, R.D. \& Sevick R.A. (2005). Relationship Between Home Literacy Environment and Reading Achievement in Children with Reading Disabilities. Journal of Learning Disabilities, 38(1), 2-11.

This Article is brought to you for free and open access by the Department of Psychology at ScholarWorks @ Georgia State University. It has been accepted for inclusion in Psychology Faculty Publications by an authorized administrator of ScholarWorks @ Georgia State University. For more information, please contact scholarworks@gsu.edu. 


\title{
Relationship Between Home Literacy Environment and Reading Achievement in Children with Reading Disabilities
}

\author{
Fontina L. Rashid, Robin D. Morris, and Rose A. Sevcik
}

\begin{abstract}
Past research has indicated that a significant relationship exists between young children's early home literacy environment and their reading-related skills. However, this relationship has rarely been investigated among older children with reading disabilities (RD). In the present study, the relationship between parent and child home literacy activities and children's academic functioning was investigated with a sample of 65 elementary-age children with RD. The results indicated that children's home literacy activities were not significantly related to any of their academic abilities, whereas parents' home literacy activities were significantly related to children's passage comprehension and spelling scores. However, relationships between home literacy environment and reading may be different for children with and without RD.
\end{abstract}

The home environment has been considered critical in the development of a variety of cognitive and linguistic skills that have been shown to be important factors in early literacy development (Saracho, 1997b). Adams (1990), in her extensive review, identified reading aloud to children as one of the most important activities for building the skills necessary for early reading. Shared reading is believed to aid in the development of word knowledge, understanding the meaning of print, and awareness of written letters and words (Senechal, LeFevre, Thomas, \& Daley, 1998). Adams (1990) estimated that children who are read to for approximately 30 minutes each night will have acquired at least 1,000 hours of print exposure when they begin kindergarten. This extensive print expo- sure is seen as an important prerequisite for children to begin to understand the phonemic structure of language and to readily identify letters.

Vygotsky (1978) highlighted the importance of social context (see Ma- son \& Allen, 1986, for a review) for language acquisition and underscored the significance of the use of scaffolding by more advanced users of the skill in development. Young children who are guided through the reading process by their parents learn strategies related to information processing, learn more advanced vocabulary, and are assisted in understanding aspects of the reading experience that are not well under- stood when reading alone (Leseman \& de Jong, 1998). But, as Heath's (1983) extensive research indicates, there still may be important environmental differences between families in their use of language and print that are related to levels of academic functioning for some children in their later school years. Whether the family literacy environment affects reading and other academic functioning or the level of a child's reading or academic functioning affects home reading activities in the family is still an open question.

The term home literacy environment generally has referred to participation in literacy-related activities in the home, which can include aspects of exposure (availability of print material) and frequency of reading (Leseman \& de Jong, 1998). Saracho (1997a) proposed that parents' literacy level and the avail- ability of reading materials are the primary characteristics of the home environment related to a child's literacy development. Leseman and de Jong (1998) further suggested that there are three aspects of the home literacy environment that are important for the development of literacy: opportunities for practice, promotion of literacy activities by literate family members, and motivation. More recent studies have extended the scope of the home literacy environment (Christian, Morrison, \& Bryant, 1998; Griffin \& Morrison, 1997; Payne, Whitehurst, \& Angell, 1994) to include such aspects as the age of the child when joint book reading began, independent child or caregiver reading, frequency of library visits, and frequency of behaviors that interfere with reading (e.g., television viewing). The potential influence of the parent as a model for literacy activity also has been considered an important element in defining the home literacy environment (Teale, 1986). These ideas have led some researchers to include questions about parent book reading and newspaper or magazine subscriptions as a separate component of home 
literacy activities (Payne et al., 1994; Scarborough, Dobrich, \& Hager, 1991), whereas others have included information about parent reading as part of a larger construct that also included child activities (Griffin \& Morrison, 1997).

Many early studies emphasized the potential differences in home literacy environment across socioeconomic status. Results from this research suggested that parent-child joint storybook reading in samples of working-class families was limited (Anderson \& Stokes, 1984; Teale, 1986). In a sample of Mexican American families, Laosa (1982) found that mothers who were more educated read to their children more often than mothers with less education. In a comparison of Mexican American and European American samples, he found that ethnic differences in parent-child reading became nonsignificant after controlling for maternal education. The absence of early literacy experiences is believed to place working-class children at a disadvantage when learning to read, especially with regard to reading comprehension (Mason \& Allen, 1986). At the same time, the observed variability even among low-income families (Teale, 1986) has led some to propose that the literacy characteristics of the home environment should be the variable of study (Scott-Jones, 1984), as measures of SES alone do not capture the environmental and behavioral differences that may provide more accurate information about relationships with child literacy functioning. A meta-analysis of 101 related studies by White (1982) also suggested that when the home atmosphere (e.g., parents' attitude toward education, parents' aspirations for their children, cultural and intellectual activities of the family) was used as an indicator of SES, relatively high correlations were found between SES and academic achievement. Although parent education, occupation, and income have been found to be related to children's reading outcomes, the actual characteristics of the atmosphere that is created by the parents or the child may be more important (Raz \& Bryant, 1990).

The majority of studies in this area have used parent self-report questionnaires focused on child activities to obtain data about the home literacy environment. Recently, some researchers have attempted to design other types of measures to provide alternative observations about the home literacy environment as well as information about individual parent reading practices. For example, Senechal, LeFevre, Hudson, and Lawson (1996) created a title recognition test (adapting methods used by Stanovich and West, 1989) and had parents complete the form as an estimate of exposure to both child and adult print. Performance on this measure of book exposure was significantly related to expressive language after controlling for estimated intelligence, parent reading activities, and parent education in a sample of 4-year- old children. The results of this study revealed a positive correlation between individual parent reading activities and child language scores; however, other researchers found no significant relationship between parents' individual reading practices and child functioning (Payne et al., 1994; Scarborough et al., 1991).

In a recent study, Frijters, Barron, and Brunello (2000) combined the use of a title recognition measure and a home literacy environment questionnaire to provide a composite of home literacy activities. The results of this study indicated that home literacy was significantly related to a child's letter- name and sound knowledge and receptive vocabulary. Frijters et al. also discovered that phonological awareness mediated the relationship between home literacy and letter-name and sound knowledge.

The recent focus of research has been on the relationship between home literacy environment and specific reading measures or other academic outcomes, as previous studies have focused primarily on the importance of the home environment during early reading acquisition. This research has included longitudinal studies and the participation of older children in study samples. Wells (1985) revealed that knowledge of literacy (concepts about print and letter identification), measured at school entry, was significantly related to reading attainment 2 years later. Cunningham and Stanovich (1991) found a significant relationship between knowledge of children's book titles and performance on measures of phonological coding, spelling, word identification, verbal fluency, receptive vocabulary, and general information after controlling for age and general ability with fourth- through sixth-grade children. Griffin and Morrison (1997) developed the nine-item Family Literacy Environment Scale for a longitudinal study of kindergarten children. Their results revealed that home literacy environment was significantly related to receptive vocabulary, general knowledge, and reading recognition, but not to mathematics scores, in kindergarten children after controlling for demo- graphic variables. There continued to be a significant relationship between home literacy environment, general knowledge, and reading ability for this sample at the end of second grade. In 1998, Christian et al. corroborated in part that family literacy environment was related to several academic out- comes, with the exception of mathematics, in a sample of 5-year-old children.

There is a surprising dearth of research on the home literacy environment of children with learning disabilities, especially reading disabilities (RD). The home literacy experiences of children with $\mathrm{RD}$ may be particularly unique, given that the child's difficulty with reading and the parent's potential difficulty with reading are likely to affect home literacy activities. Moreover, it is not known whether a relationship between home literacy and reading achievement exists for children with RD. Information on the home experiences of this subgroup of children could be helpful for understanding 


\section{[Type here]}

their reading development and potentially improving interventions.

In one of the few studies that examined the literacy environment of a specific population of children with disabilities, Marvin and Wright (1997) compared the home literacy experiences of 3- to 5-year-old children with speechlanguage impairments, children with physical or other disabilities, and children with no delays. Their results indicated that children with speech-language impairments were not as actively involved in reading activities as the other groups. Parents of children with disabilities also did not place a high priority on the development of reading and writing skills, as they reported greater concern with the development of self-help and communication skills. These results have implications for the potential differences between the home environments created by parents of children with and without disabilities.

In another study, by Hughes, Schumm, and Vaughn (1999), parents of Hispanic children with learning dis- abilities indicated that their child's difficulty with reading and writing was a barrier to implementing reading-related activities in the home. On the other hand, the results of this study indicated no differences between children with learning disabilities and those without learning problems in home reading and writing activities. This investigation suggested that the home literacy environment of children with learning disabilities may be similar to that of children without disabilities in terms of frequency and type of reading activity. However, the sample included only Hispanic participants, which limits the generalizability of the findings.

More data are needed to establish an understanding of the relationship between home literacy environment and level of academic functioning for children with RD. It has been well documented that the home literacy environment is associated with the level of reading-related skills in children with- out disabilities. Moreover, differences across lower and middle class groups were found to be related to the actual atmosphere created by the parents in their homes. Overall, research suggests that home literacy may be another important factor in literacy development and that literacy level may have an impact on home literacy activities apart from predictors such as SES, parent education level, and child IQ.

The present study examined the home literacy environment of children diagnosed with RD. Information about child and parent individual reading activities was gathered, as well as information about joint reading activities. The quality of the home literacy environment was explored to determine the variety of literacy experiences available in the homes of children with RD. The question of whether a significant relationship exists between home literacy environment and reading achievement scores was also addressed. Based on previous research that indicated positive correlations between individual parent literacy activities and child outcomes, both parent and child home literacy activities were considered as potential factors related to child achievement. Consistent with findings from previous studies (Payne et al., 1994; Scarborough et al., 1991), we hypothesized that the child's actual reading exposure is a more significant factor in predicting reading level than the parents' individual reading activities.

\section{Method}

\section{Participants}

Participants were 65 children with RD and their primary caregivers. The children were recruited from five elementary schools in a large southeastern metropolitan city. Students were initially identified by their teachers as having difficulty with learning to read. Inclusion criteria were as follows: English as the primary language, chronological age between 6-6 and 8-6, Grade 1 or 2 at time of screening, hearing and vision within typical limits, and either European American or African American ethnicity. Children were excluded if they had repeated a grade in school, achieved an IQ score below 70, or had a significant psychiatric or neurological disorder. Children from above-average and below-average socioeconomic levels were systematically included. The Four-Factor Index of Social Status (Hollingshead, 1975) was used to calculate the socioeconomic status of the families in the study.

Children were included in the study if they met either a low achievement-based or an IQ-achievement discrepancy-based definition for RD. The Kaufman Brief Intelligence Test (K-BIT; Kaufman \& Kaufman, 1990) composite standard score was used as the proxy measure of intellectual ability, and the Woodcock Reading Mastery TestRevised (WRMT-R; Woodcock, 1987) and Wide Range Achievement Test-3 (WRAT-3; Wilkinson, 1993) reading subtests were used to determine reading level. Three combinations of reading scores were used to provide an index of reading achievement: the average of standard scores obtained on WRMT-R Passage Comprehension, Word Identification, Word Attack, and WRAT-3 Reading; the standard score obtained on the WRMT-R Basic Skills composite score (Word Identification, Word Attack); or the standard score obtained on the WRMT-R Total Reading composite score (Word Identification, Passage Comprehension). Participants met criteria for the low achievement-based definition if one of the three reading index scores was 85 or less. Participants were included under the discrepancy-based definition if their reading index score was more than one standard error of the estimate below the expected reading achievement based on their IQ. 


\section{[Type here]}

\section{Procedure}

Children who met the criteria for the study completed tests of reading skill and cognitive ability in the fall of their secondor third-grade year. Parents of the children in the study were asked to complete a questionnaire by telephone, which included items regarding the child's early development, home literacy activities, family demographics, and social support; 58 of the primary caregivers who completed the inter- view were mothers, 3 were grand- mothers, 3 were fathers, and 1 set of parents answered the questions together.

\section{Measures}

Background Information. Questionnaires completed by the parents indicated the child's age, ethnicity, and sex. Furthermore, parents provided in- formation about their education level (years of formal schooling) and occupation, which was used to develop an index of SES (Hollingshead, 1975).

IQ. The child's IQ, as measured by the Wechsler Intelligence Scale for Children-Third Edition (WISC-III; Wechsler, 1991), Full Scale IQ (FSIQ), was included as a factor in the study. Children completed the WISC-III during their secondor third-grade year in school.

WRMT-R. Three subtests of the WRMT-R were used as the primary measures of reading skill. The Word Identification subtest was used to measure individual word reading, the Word Attack subtest (nonword reading) was used to measure phonetic decoding skills, and the Passage Comprehension subtest was used to mea- sure reading comprehension. The Basic Skills cluster, a decoding composite score including Word Identification and Word Attack subtest scores, was used in this study along with the Pas- sage Comprehension subtest.

WRAT-3. This test contains three subtests that measure reading, mathematics, and spelling skills. The arithmetic and spelling subtests were used to better differentiate the specific relationship between home literacy activities and reading from other academic skills.

Comprehensive Family Questionnaire. To provide information about each child's home environment and family background, a comprehensive questionnaire was developed. The 51-item questionnaire includes developmental information, family medical and school history, home literacy activities, parental beliefs about education and related activities, family demographics, and social support. A subset of 13 questions was used as a measure of family literacy environment, including 6 questions about the parents' literacy activities and 7 questions about the child's literacy activities (see Note). Literacy-related questions were based on previous home literacy environment scales developed by Payne et al. (1994) and Griffin and Morrison (1997).

Four of the six questions regarding parents' literacy activities were taken from Griffin and Morrison (1997). In some cases, the wording was changed to provide more specific in- formation. For example, instead of questioning parents about how many newspaper subscriptions they had, we asked how often they read a newspaper, which broadens the range of possible responses. Two additional questions about parent literacy activities (not included in Griffin and Morrison's measure) were also added to the questionnaire. First, we asked parents about their reading ability, as this may influence the literacy environment that is created in the home. Second, a question about the frequency of parent television viewing was included to ex- amine the impact of nonreading behaviors.

Items were classified as child literacy items if the activity included the child as a participant. These items included five questions taken from Payne et al. (1994); three of these questions were also used by Griffin and Morrison (1997). These questions examined the frequency of the child reading alone, frequency of the child reading with the caregiver, library visits, number of books the child owned, and the age of the child when others began reading to him or her. Based on the questionnaire created by Griffin and Morrison, two items related to the child's nonreading behavior (television viewing) were also included. Whereas Griffin and Morrison asked about the frequency of television viewing in general, our questionnaire separated entertainment and educational television programs, resulting in two additional questions.

An index of child or parent home literacy environment was obtained by assigning point values of 1 to 5 (with 1 indicating least frequent literacy- related activities and 5 indicating most frequent literacy-related activities) to the responses to each of the questions. One question, regarding the ownership of a library card, was scored either 0 or 1 point. Scores on the three items related to television viewing were reversed, as reflective of reading-interfering behaviors ( 1 indicating most frequent television viewing and 5 indicating least frequent television viewing). Items were summed to provide an index of literacy activities, and possible scores ranged from 5 to 27 for parent activities and from 7 


\section{[Type here]}

to 35 for child activities.

Item intercorrelations for the home literacy items are presented in Table 1. As expected, there were small but significant correlations between many of the home literacy items. In general, there tended to be higher correlations within parent and child literacy indices than across parent and child items, with a few expected exceptions. Thus, the parent's ownership of a library card was significantly related to the frequency of the child's library visits. It would be expected that parents who do not own a library card may be less likely to take their child to the library regularly. Similarly, the amount of television watched by the parent was correlated significantly with the amount of television watched by the child, suggesting a pattern of household television viewing. Additional correlations suggested that parent reading or reading-interfering behaviors were related to the age of the child when the parent began joint reading

TABLE 1

Item Intercorrelations for the Home Literacy Measure

\begin{tabular}{|c|c|c|c|c|c|c|c|c|c|c|c|c|c|}
\hline Item & 1 & 2 & 3 & 4 & 5 & 6 & 7 & 8 & 9 & 10 & 11 & 12 & 13 \\
\hline 1. Parent reading ability & - & $.48^{* *}$ & .20 & .19 & -.09 & .02 & .06 & .16 & .02 & -.19 & .03 & .00 & .14 \\
\hline 2. Parent-books read in year & & - & .05 & .21 & -.01 & $.40^{* *}$ & .07 & .28 & .05 & .14 & .19 & -.00 & .11 \\
\hline 3. Parent owns library card & & & - & .09 & -.08 & .14 & .15 & -.07 & $.34^{* *}$ & -.05 & $.32^{* *}$ & .10 & .22 \\
\hline 4. Parent magazine reading & & & & - & .20 & .16 & -.04 & $.32^{* *}$ & .22 & -.16 & .19 & -.04 & .17 \\
\hline 5. Parent newspaper reading & & & & & - & -.14 & .04 & .11 & -.06 & -.08 & -.03 & -.04 & .11 \\
\hline 6. Parent TV viewing & & & & & & - & .07 & $.25^{*}$ & -.05 & .17 & .22 & .22 & $.38^{* *}$ \\
\hline 7. Joint reading & & & & & & & - & .23 & .19 & .03 & $.30^{*}$ & .10 & .12 \\
\hline 8. Age of child when first read to & & & & & & & & - & .01 & .10 & $.36^{* *}$ & .11 & $.27^{*}$ \\
\hline 9. Child library visits & & & & & & & & & - & .16 & .06 & .11 & .05 \\
\hline 10. Child independent reading & & & & & & & & & & - & .03 & .14 & .12 \\
\hline 11. Number of books child owns & & & & & & & & & & & - & .10 & $.34^{* *}$ \\
\hline 12. Child-educational TV & & & & & & & & & & & & - & $.33^{* *}$ \\
\hline 13. Child-other TV & & & & & & & & & & & & & - \\
\hline
\end{tabular}

${ }^{*} p<.05 .{ }^{*} p<.01$.

An exploratory factor analysis was completed, using the present sample of 65 children, to test the theoretically driven design of the home literacy environment questionnaire. A two-factor solution revealed that questions associated with child activities loaded on one factor, whereas parent activities loaded on a second factor, with a few exceptions. Two items loaded on both factors (parent television viewing and the age the child was first read to), and one parent literacy question (the parent's ownership of a library card) loaded on the factor that included child literacy questions. It is recognized that a factor analysis with a sample of this size makes clear interpretations limited. The limitations associated with the use of a sample of children with RD are also acknowledged-particularly, the likelihood of a restricted range of responses. How- ever, the factor analysis supported the conceptual framework that guided the separation of home literacy questions into child and parent home literacy factors.

\section{Results}

\section{Participant Characteristics}

The mean age of the 65 children in the study was 7.6 years ( $\mathrm{SD}=0.53$ ), and 44 of the participants were boys. In general, the sample included children whose FSIQ was low average compared to normative data $(\mathrm{M}=85.8, \mathrm{SD}=12.7)$. The majority of the children were African American $(n=48)$, and the parents of the children had completed an average of 13.1 years $(\mathrm{SD}=2.1)$ of education. As would be expected given the inclusion criteria for the study, families of low SES $(\mathrm{n}=27)$ and average or above-average SES $(n=38)$ were almost equally represented. Table 2 displays correlations be- tween the demographic, literacy, and academic variables. There were small but significant correlations between race and IQ, mother's education and literacy score, and child age and several of the academic and literacy variables. There was also a small but significant correlation between child and parent literacy scores. As would be expected, FSIQ was significantly correlated 
with the academic measures, and there were significant correlations among the academic variables.

As Table 3 shows, children in the sample typically scored below the normative mean across academic subjects. As would be expected in a sample of children with $\mathrm{RD}$, the mean reading scores were more than $1 \mathrm{SD}$ below average. The children in this sample tended to perform better on measures of arithmetic and spelling, although their performance was still below the normative mean.

\section{Child Literacy Data}

Examination of the responses to the child literacy questions revealed that the literacy experiences in the home varied greatly within the sample. Al- though many of the children engaged in several literacy-related activities in the home and had access to reading materials, a large percentage of the children did not engage in many reading activities and spent several hours engaged in nonreading behaviors (i.e., watching television).

\section{TABLE 2}

Intercorrelations Between Demographic, Literacy, and Achievement Variables

\begin{tabular}{|c|c|c|c|c|c|c|c|c|c|c|c|}
\hline Variable & 1 & 2 & 3 & 4 & 5 & 6 & 7 & 8 & 9 & 10 & 11 \\
\hline 1. FSIQ & - & .17 & $-.49^{* *}$ & -.35 & $.36^{* *}$ & .17 & $.32^{*}$ & $.41^{* *}$ & $.39 * *$ & $.47^{\star *}$ & $.40^{* *}$ \\
\hline 2. Gendera & & - & .04 & -.19 & .24 & -.01 & .11 & -.02 & -.01 & .08 & -.11 \\
\hline 3. Raceb & & & - & .05 & -.24 & -.18 & -.17 & -.24 & -.19 & -.07 & -.20 \\
\hline 4. Child Age & & & & - & -.27 & -.06 & $-.25^{*}$ & $-.38^{* *}$ & $-.34^{* *}$ & $-.37^{\star *}$ & $-.25^{*}$ \\
\hline 5. Maternal Education & & & & & - & .19 & $.40^{* *}$ & .22 & .25 & .06 & .15 \\
\hline 6. Child Home Literacy Score & & & & & & - & $.38^{* *}$ & .17 & .16 & .14 & .09 \\
\hline 7. Parent Home Literacy Score & & & & & & & - & $.33^{* *}$ & $.41^{* *}$ & .11 & $.37^{* *}$ \\
\hline 8. WRMT-R Basic Skills & & & & & & & & - & $.83^{* *}$ & $.56^{* *}$ & $.80^{* *}$ \\
\hline 9. WRMT-R Passage Comprehension & & & & & & & & & - & $.57^{* *}$ & $.75^{* *}$ \\
\hline 10. WRAT-3 Arithmetic & & & & & & & & & & - & $.53^{* *}$ \\
\hline 11. WRAT-3 Spelling & & & & & & & & & & & - \\
\hline
\end{tabular}

Note. WRMT-R = Woodcock Reading Mastery Test-Revised (Woodcock, 1987); WRAT-3 = Wide Range Achievement Test-3 (Wilkinson, 1993); FSIQ = Full Scale IQ.

${ }^{a}$ Gender was coded as $0=$ girl, 1 = boy. ${ }^{b}$ Race was coded as $0=$ European American, $1=$ African American.

" $p<.05 .{ }^{*} p<.01$. 
Approximately $22 \%$ of the children were read to seven to nine times per week; however, more than $60 \%$ of the children were read to fewer than three times per week. Approximately half of the children were first read to before the age of $1(57 \%)$. Another $30 \%$ of the sample were not read to until they were more than 3 years old, if at all. More than half of the sample never visited the library. At least $50 \%$ of the children owned 30 books or more, whereas approximately $27 \%$ owned fewer than 20 books. With regard to the child's individual activities, more than $50 \%$ of the children read or looked at books alone at least once per day. At the same time, $20 \%$ of the children never read or looked at books alone at home. The children in the sample rarely watched educational programs on television; however, more than $60 \%$ watched 2 hours or more of entertainment television per day.

\section{Parent Literacy Data}

Similar to the child literacy experiences, the literacy activities of the parents varied across the sample. Most parents reported themselves to be average or above-average readers $(89 \%)$ and indicated that they owned a library card $(63 \%)$. The parents' reading and nonreading behaviors were more variable. Whereas $27 \%$ of parents read more than 10 books per year, $43 \%$ read 2 or fewer books per year. Approximately $83 \%$ of the parents read the newspaper occasionally, and $46 \%$ read two or more magazines regularly. An- other 45\% never read magazines, and 15\% did not care to read the newspaper. Thirty percent reported that they watched 3 hours of television or more per day.

\section{Literacy Environment as Predictor of Reading Achievement}

A hierarchical multiple regression analysis was performed using decoding skills as the dependent variable and child and parent literacy scores as the predictor variables. After controlling for the effect of FSIQ and maternal education, R2 $=.17$, $\mathrm{p}<.01$, neither of the literacy variables accounted for a significant amount of additional variance in decoding scores. A second hierarchical multiple regression examined the amount of variance in WRMT-R Pas- sage Comprehension scores accounted for by child and parent literacy. Parent literacy accounted for a significant amount of additional variance, $\Delta \mathrm{R} 2$

\begin{tabular}{lcr}
\hline \multicolumn{2}{c}{ TABLE 3 } & \\
\multicolumn{1}{c}{ Means and Standard Deviations for Literacy and Achievement Variables } \\
\hline \multicolumn{1}{c}{ Variable } & $\boldsymbol{M}$ & SD \\
\hline Child Home Literacy (raw score) & 19.31 & 4.55 \\
Parent Home Literacy (raw score) & 14.66 & 3.00 \\
WRMT-R Basic Skills (SS) & 73.74 & 11.66 \\
WRMT-R Passage Comprehension (SS) & 76.26 & 13.96 \\
WRAT-3 Arithmetic (SS) & 85.34 & 12.08 \\
WRAT-3 Spelling (SS) & 81.52 & 8.42 \\
\hline
\end{tabular}

Note. $N=65$. WRMT-R = Woodcock Reading Mastery Test-Revised (Woodcock, 1987); WRAT-3 = Wide Range Achievement Test-3 (Wilkinson, 1993); SS = standard score.

$=.07, \mathrm{p}<.05$, after controlling for FSIQ and maternal education, $\mathrm{R} 2=.17, \mathrm{p}<.01$. The results of these regression analyses are presented in Table 4.

\section{Literacy Environment as Predictor of Arithmetic and Spelling}

A hierarchical multiple regression analysis with arithmetic scores as the dependent variable and child and parent literacy scores as the independent variables was also performed. As predicted, neither of the literacy scores accounted for a significant amount of variance in arithmetic scores after con- trolling for the covariates. A second regression analysis examined the relationship between the literacy variables and spelling. After controlling for FSIQ and maternal education, parent literacy accounted for a significant amount of additional variance in spelling scores, $\Delta R 2=.07, p<.05)$. The results from these regression analyses are presented in Table 4.

\section{Discussion}


The present study examined the relationship between home literacy environment and early reading achievement in children with RD. Home literacy environment was conceptualized as parent- and child-specific home reading and nonreading activities. The results revealed that child home literacy experiences did not account for a significant amount of variance in decoding, reading comprehension, spelling, or arithmetic after controlling for child IQ and maternal education level. Parent home literacy experiences did account for a significant amount of variance in children's reading comprehension and spelling scores after con- trolling for child IQ and maternal education. As expected, home literacy was not related to arithmetic scores, which suggests that the data obtained from the literacy questionnaire were specific to reading.

The results indicate that although individual child and joint home literacy experiences may be significantly related to prereading skill (language, phonological awareness) — as has been found in other studies — the more direct relationship between home literacy and actual reading achievement is less robust, at least among children with early-identified RD. The results of this study also suggest that parent home literacy activities may be a more important factor in understanding child reading than activities involving the child more directly. It may be that the parents' reading activities provide more valid information about the home literacy environment or that parents can provide more accurate data about their own reading activities than about those of their children. It is also important to note that this relationship may represent the cumulative effect of parent literacy activities over time. Un- fortunately, there have been no similar studies that can provide comparable data, which makes it difficult to deter- mine whether the home literacy experiences of these children represent substantial opportunities or very few opportunities for practice. It may be that the overall experiences of these children are too limited and, therefore, cannot have a significant impact on their reading achievement alone. 
Predicting Academic Achievement

\begin{tabular}{|c|c|c|c|c|}
\hline Variable & $R^{2}$ & $\Delta R^{2}$ & $s r^{2}$ & $\beta$ \\
\hline \multicolumn{5}{|c|}{ WRMT-R Basic Skills } \\
\hline Step 1 & $.17^{* *}$ & $.17^{* *}$ & & \\
\hline FSIQ & & & .09 & .33 \\
\hline Maternal Education & & & .00 & .01 \\
\hline Step 2 & .18 & .01 & & \\
\hline Child Home Literacy & & & .00 & .03 \\
\hline Step 3 & .21 & .03 & & \\
\hline Parent Home Literacy & & & .03 & .21 \\
\hline
\end{tabular}

WRMT-R Passage Comprehension

Step 1

FSIQ

Maternal Education

Step 2

Child Home Literacy

Step 3

Parent Home Literacy
$.17^{* *}$

$.17^{* *}$

.17

$.25^{*}$

01

$.07^{*}$
.29

.02

.00

.00

$-.02$

.07

.32

WRAT-3 Arithmetic

Step 1

FSIQ

Maternal Education

Step 2

Child Home Literacy

Step 3

Parent Home Literacy
$.24^{* *}$

.24

.24

WRAT-3 Spelling

Step 1

FSIQ

Maternal Education

Step 2

Child Home Literacy

Step 3

Parent Home Literacy
$.16^{* *}$

.16

$.24^{*}$
$.24^{* *}$

.01

.00

.01

.00
.51

$-.13$

.09

$-.03$

\section{3} (3) 21 
1997; Payne et al., 1994). Although it appears that the actual home environment—as opposed to ethnicity or SES—may have a more significant relationship with academic functioning, it still may be important to consider the potential impact of both ethnic back- ground and SES on the characteristics of a sample.

The age of the participants in this sample was also different from that in other studies. This sample included an older group of children (age range 6-9 years) than many of the previous studies. Prior samples included mostly preschoolor kindergarten-age children, with only two studies focused on children in second grade or higher (Griffin \& Morrison, 1997; Hughes et al., 1999).

The sample size $(\mathrm{N}=65)$ in this study was smaller than only a few previous studies that used similar designs and measures (Christian et al., 1998; Griffin \& Morrison, 1997). However, when comparing the actual variances accounted for in this study and the Griffin and Morrison study, the results are somewhat similar. The R2 for home literacy predicting reading recognition in Griffin and Morrison's study was .012, whereas in the present study, the value for child literacy predicting de- coding was .008. Interesting enough, in the present study, parent home literacy accounted for more variance in decoding scores, $\mathrm{R} 2=.038$, ns, than did home literacy in Griffin and Morrison's study.

Aside from the differences in sample characteristics and sample size, the present study also differed in terms of the methodology and measures used to investigate home literacy. Given that most earlier studies included children 5 years of age or younger, few have examined the impact or relationship with children's actual reading achievement, focusing instead on language or phonological awareness. Thus, the reciprocal link be- tween home literacy and reading ability has not been evaluated in many studies (Burgess, 1997; Payne et al., 1994; Senechal et al., 1996). Most previous studies also mailed questionnaires to parents for completion. This may result in a restricted sample if parents with limited reading ability fail to complete the surveys. Parents of children with RD may have reading difficulties themselves, making independent completion of questionnaires difficult. In the present study, questionnaires were completed by phone interview to address this issue. At the same time, the use of phone interviews may have resulted in parents providing responses that were more socially desirable, as opposed to accurately representing their home literacy environments. Although the use of phone interviews reduced the chance of selectively removing parents with limited reading ability from the study and allowed for clarification of responses, the issue of social desirability must be considered, although this issue is also of concern when using paper questionnaires.

Another methodological difference was that some prior studies did not control for the influence of IQ, language differences, SES, or maternal education level on reading or reading- related skills. Whereas many studies controlled for some of these important factors statistically, others did not con- sider the impact of these background or predictor variables. Failure to include these variables as covariates likely resulted in an overestimate of the relationship between home literacy environment and academic achievement or reading-related skills.

With regard to comparability of measurements, there has been considerable variability in the measures used to assess home literacy, academic achievement, or background variables. Moreover, few studies have examined parent literacy activities independently. This makes comparison across studies difficult. Whereas previous studies used between one and nine questions to measure overall home literacy, the questionnaire used in this study included six questions related to parent home literacy and seven questions related to child home literacy. The inclusion of the parents' individual reading activities within the same scale as the child's reading activities in previous studies made it unclear which specific aspects of the literacy environment were related to the child's language or academic achievement. Based on the present study's results, it can be suggested that the parental activities are the more significant factors accounting for important shared variance with child reading abilities in previous studies. Parent and child literacy items were combined in an exploratory analysis using data from the present study. Interesting enough, the composite measure of home literacy did not ac- count for significant variance in any of the child achievement scores. This finding further emphasizes the importance of examining the specific aspects of the home literacy environment that are related to academic outcomes.

The present study also improved on past studies by controlling for FSIQ using the WISC-III, as opposed to the abbreviated measures used previously (Christian et al., 1998; Griffin \& Morrison, 1997; Senechal et al., 1996, 1998). With the absence of comparable measures of IQ (or the absence of IQ data), it is difficult to determine whether the same aspects of the child's cognitive functioning have been integrated statistically—and adequately—across studies. This is an important consideration, given the significant correlation between IQ and indices of home literacy (Christian et al., 1998; Griffin \& Morrison, 1997).

Although the use of the WISC-III in the present study represents some improvement over past studies, its use may also 
have accounted for significantly more variance in outcome variables than what had been accounted for by the abbreviated measures used previously. Examination of previous studies revealed that abbreviated IQ measures accounted for between $2 \%$ and $10 \%$ of the variance in reading scores, which is significantly lower than the variance accounted for by FSIQ in the present study $(16 \%-17 \%)$. The relationship between IQ and reading achievement based on national standardization samples is approximately 30\% (Woodcock, 1987). Com- pared to previous studies, the inconsistency in the results may be due to limited sample size, limited measurement of IQ, or the way IQ was used in the analyses.

It appears that measures of home literacy environment are related to the underlying language skills necessary for reading acquisition; however, their relationship with reading performance is less clear. This may suggest that the home literacy environment has a greater impact on early reading development but is less significant once the child has learned to read. The finding that parent literacy activities were significantly related to reading comprehension and spelling may also indicate that although early literacy experiences are important for reading acquisition, these experiences may have a greater impact on the development of more advanced reading and written language skills once the child begins instruction in school. It may be that an environment rich in literacy experiences increases general vocabulary and language abilities and, therefore, aids the understanding of the meaning of print as opposed to decoding skills for school-age children. The reciprocal may also be true- that through learning to read, children increase their vocabulary and language abilities, which affects their families' literacy activities due to the children's added competence or lack thereof. In support of this idea, Senechal et al. (1998) found that storybook exposure predicted oral language but not reading ability, suggesting a less direct relationship between home literacy and reading ability in a sample of first-grade children.

However, the findings of the present study suggest that the relationship between home literacy and reading level may be different for children who have difficulty with early reading. It may be that a child with RD engages in fewer home literacy activities due to his or her limited reading skills. It also may be the case that children with RD continue to have difficulty despite a equate exposure to literacy activities in their home, or that parents of children with RD do not emphasize literacy activities in the home because of their children's difficulty with reading (and, in some cases, their own difficulties with reading). A clearer understanding of how reading problems affect the home literacy environment is an important question for future study.

Given the lack of consensus regarding how best to measure the home literacy environment, the development of a reliable and valid measure of this construct is crucial to the future development of this area of research. The interpretation of research results and comparisons across all studies is challenged by the use of different measures and methods across studies. It will be important to complete more longitudinal studies in this area, such as those by Christian et al. (1998) and Griffin and Morrison (1997). Previous studies have primarily examined the relation- ship between home literacy and early language skills with younger children, whereas few studies have focused on older children, and those that have done so have yielded inconsistent results. Therefore, it will be critical for the field to continue to evaluate the influence of home literacy on child academic performances and the influence of child reading abilities on home literacy activities over time. 


\section{ABOUT THE AUTHORS}

Fontina L. Rashid, PhD, is a research associate at the Regents Center for Learning Disorders at Georgia State University. Her current interests include the relation between home literacy environment and reading disability and the assessment of attention-deficit/hyperactivity disorder and learning disabilities. Robin D. Morris, PhD, is a Regents Professor of Psychology and Associate Dean for Research and Graduate Studies at Georgia State University. His research explores reading development and reading disabilities, basic issues related to nervous system development, the development of higher cognitive abilities, and applied issues focused on developmental or acquired brain dis-orders in children and young adults. Rose A. Sevcik, PhD, is an associate professor of psychology at Georgia State University. She is a developmental psychologist whose research centers on the development of symbolic processes, specifically oral and written language development. Address: Fontina L. Rashid, Regents Center for Learning Disorders, Georgia State University, PO Box 3984, Atlanta, GA 30302-3984. 


\section{AUTHORS' NOTES}

1. Support for this research was provided by National Institute of Child Health and Human Development Grant HD30970.

2. This article is based on the dissertation research of the first author.

3. We thank the families who agreed to participate in this research.

\section{NOTE}

1. A copy of the home literacy questionnaire used in this study can be provided on request.

\section{REFERENCES}

Adams, M. J. (1990). Beginning to read: Thinking and learning about print. Cambridge, MA: MIT Press.

Anderson, A. B., \& Stokes, S. J. (1984). Social and institutional influences on the development and practice of literacy. In H. Goelman, A. Oberg, \& F. Smith (Eds.), Awakening to literacy (pp. 24-37). Exeter, NH: Heinemann.

Burgess, S. (1997). The role of shared reading in the development of phonological awareness: A longitudinal study of middle to upper class children. Early Child Development and Care, 127-128, 191-199.

Christian, K., Morrison, F. J., \& Bryant, F. B. (1998). Predicting kindergarten academic skills: Interactions among child care, maternal education, and family literacy environments. Early Childhood Research Quarterly, 13, 501-521.

Cunningham, A. E., \& Stanovich, K. E. (1991). Tracking the unique effects of print exposure in children: Associations with vocabulary, general knowledge, and spelling. Journal of Educational Psychology, 83, 264-274.

Frijters, J. C., Barron, R. W., \& Brunello, M. (2000). Direct and mediated influences of home literacy and literacy interest on prereaders' oral vocabulary and early written language skill. Journal of Educational Psychology, 92, 466-477.
Griffin, E. A., \& Morrison, F. J. (1997). The unique contribution of home literacy environment to differences in early literacy skills. Early Child Development and Care, 127-128, 233-243.

Heath, S. B. (1983). Ways with words: Language, life, and work in communities and classrooms. New York: Cambridge University Press.

Hollingshead, A. N. (1975). Four factor index of social status. Unpublished manuscript, Yale University, New Haven, CT.

Hughes, M. T., Schumm, J. S., \& Vaughn, S. (1999). Home literacy activities: Perceptions and practices of Hispanic parents of children with learning disabilities. Learning Disability Quarterly, 22, 224-235.

Kaufman, A. S., \& Kaufman, N. L. (1990). Kaufman brief intelligence test. Circle Pines, MN: American Guidance Service.

Laosa, L. M. (1982). School, occupation, culture, and family: The impact of parental schooling on the parent-child relationship. Journal of Educational Psychology, 74, 791-827.

Leseman, P. P. M., \& de Jong, P. F. (1998). Home literacy: Opportunity, instruction, cooperation and social-emotional quality predicting early reading achievement. Reading Research Quarterly, 33, 294-318.

Marvin, C. A., \& Wright, D. (1997). Literacy socialization in the homes of preschool children. Language, Speech, and Hearing Services in Schools, 28, 154-163.

Mason, J. M., \& Allen, J. (1986). A review of emergent literacy with implications for research and practice in reading. Review of Research in Education, 13, 3-47.

Payne, A. C., Whitehurst, G. J., \& Angell, A. L. (1994). The role of home literacy environment in the development of language ability in preschool children from low-income families. Early Childhood Research Quarterly, 9, 427-440.

Raz, I. S., \& Bryant, P. (1990). Social background, phonological awareness and children's reading. British Journal of Developmental Psychology, 8, 209-225.

Saracho, O. N. (1997a). Perspectives on family literacy. Early Child Development and Care, 127-128.

Saracho, O. N. (1997b). Using the home environment to support emergent literacy. Early Child Development and Care, 201-216.
Scarborough, H. S., Dobrich, W., \& Hager, M. (1991). Preschool literacy experience and later reading achievement. Journal of Learning Disabilities, 24, 508-511.

Scott-Jones, D. (1984). Family influences on cognitive development and school achievement. Review of Research in Education, 11, 259-304.

Senechal, M., LeFevre, J., Hudson, E., \& Lawson, E. P. (1996). Knowledge of storybooks as a predictor of young children's vocabulary. Journal of Educational Psychology, 88, 520-536.

Senechal, M., LeFevre, J., Thomas, E. M., \& Daley, K. E. (1998). Differential effects of home literacy experiences on the development of oral and written language. Reading Research Quarterly, 33, 96-116.

Stanovich, K., \& West, J. (1989). Exposure to print and orthographic processing. Reading Research Quarterly, 24, 402-433.

Stevenson, H. W., Chen, C., \& Uttal, D. H. (1990). Beliefs and achievement: A study of Black, White, and Hispanic children. Child Development, 61, 508-523.

Teale, W. H. (1986). Home background and young children's literacy development. In W. H. Teale \& E. Sulzby (Eds.), Emergent literacy: Writing and reading (173206). Norwood, NJ: Ablex.

Vygotsky, L. S. (1978). The development of psychological processes. Cambridge, MA: Harvard University Press.

Wechsler, D. (1991). Wechsler intelligence scale for children (3rd ed.). San Antonio, TX: Psychological Corp.

Wells, G. (1985). Preschool literacy-related activities and success in school. In D. R. Olson, N. Torrance, \& A. Hildyard (Eds.), Literacy, language, and learning: The nature and consequences of reading and writing (pp. 229-255). Cambridge, UK: Cambridge University Press.

White, K. R. (1982). The relation between socioeconomic status and academic achievement. Psychological Bulletin, 91, 461-481.

Wilkinson, G. S. (1993). Wide range achievement test (3rd ed.). Wilmington, DE: Wide Range.

Woodcock, R. W. (1987). Woodcock reading mastery test-Revised. Circle Pines, MN: American Guidance Service. 
Copyright of Journal of Learning Disabilities is the property of PRO-ED and its content may not be copied or emailed to multiple sites or posted to a listserv without the copyright holder's express written permission. However, users may print, download, or email articles for individual use. 